\title{
Conclusion
}

\section{Seaweed invasions: conclusions and future directions}

\author{
Craig R. Johnson \\ School of Zoology and TAFI, University of Tasmania, \\ GPO Box 252-05, Hobart, Tasmania 7001, Australia, \\ e-mail: craig.johnson@utas.edu.au
}

In the introduction of this special issue of Botanica Marina, we established the scope of this topic around a series of questions, which also provided a framework for integrating the different contributions and a means of highlighting deficiencies in knowledge and understanding (Johnson and Chapman 2007). In defining challenges for the future and suggesting how those challenges might best be tackled to optimize returns on research investment, it is useful to revisit those questions under four main headings dealing with species introductions per se, the invasion process, consequences of invasions and human responses to the threat and occurrence of invasion.

\section{Introductions of alien seaweeds}

\section{The questions posed}

- What are the major modes of introduction of invasive seaweeds?

- Is there tangible pressure for ongoing intentional introductions?

\section{Accidental introductions}

Introduced seaweeds have been detected in most marine bioregions of the world, the exceptions being some tropical areas and the polar latitudes (Hewitt et al. 2007). They can account for a significant proportion of the total flora (e.g., Ribera and Boudouresque 1995) and up to $\sim 40 \%$ of all alien species (Schaffelke et al. 2006) in a given area. As is the case with most establishments of alien species, the great majority $(\sim 97 \%)$ of seaweed introductions are accidental, and hull fouling of ships is by far the most important vector (Hewitt et al. 2007). These observations pose two challenges, namely ascertaining the veracity of current knowledge about the extent of alien and invasive seaweeds, and whether there are meaningful responses to reduce the risk of introductions through hull fouling.

Particularly in the last decade, there has been an accelerated effort to detect introduced seaweeds to the extent that up to $\sim 260$ species world wide have now been identified as alien to their native range (Hewitt et al. 2007). However, there is at least a qualitative correlation between the number of alien species recorded in IUCN bioregions and the effort given to looking for them. Regions where interest among phycologists, authorities and the public alike has driven a large effort to detect alien species (Mediterranean), or where systematic surveys of susceptible areas (ports) have been implemented (Australia and New Zealand), reveal the greatest number of alien seaweed species. This is hardly surprising, but it begs the question about the real number of established alien seaweeds, and whether apparent patterns of larger numbers of alien seaweeds in Australia, New Zealand and the Mediterranean, but far fewer alien species in tropical waters, particularly in Africa and Asia, are real.

Just as is the case for invasions of terrestrial systems (Mack et al. 2000), preventing invasions of seaweeds in the first place is much less costly than attempting control of post-establishment. However, given that hull fouling is the principal culprit, this poses large challenges, particularly in light of the intent to phase out use of tributlytin (TBT) and related organotins in antifouling paints by $1^{\text {st }}$ January 2008 because of their deleterious effects on the marine environment. The International Maritime Organization's (IMO's) International Convention on the Control of Harmful Anti-fouling Systems on Ships prohibits the use of TBT and will enter into force 12 months after 25 States (representing $25 \%$ of the world's merchant shipping tonnage) have ratified it. The 1999 IMO Assembly resolution called for complete prohibition on the application of TBT and other organotin compounds by $1^{\text {st }}$ January 2008. Despite redoubled efforts to develop new antifouling paints based on chemical biocides less toxic than organotins, or with physical properties that inhibit settlement of marine organisms, hull fouling remains a significant problem. Engineering solutions (e.g., mechanical hull scrubbers) have presumably not been cost effective. Indeed, most engineering efforts to control translocation of marine species, including algae, by shipping have focused on treatment of ballast water (e.g., Cangelosi et al. 2007, Gollasch et al. 2007).

\section{Intentional introductions}

A minority of species $(<3 \%)$ has been introduced intentionally, usually for aquaculture, but there are likely to be ongoing appeals for future introductions. This pressure is most acute in developing nations in tropical and subtropical regions where aquaculture of seaweeds is often seen as an alternative (and sustainable) economic activity to either growing species that require large inputs of artificial feeds or extractive harvesting in wild fisheries (Pickering et al. 2007), both of which have typically had a large impact on the environment and which may be ecologically and economically unsustainable in the long term. Given large ecological pressures on coral reefs as a result of, for example, overfishing and pollution associated with 
aquaculture of species that require addition of nutrients (McManus 1997, Jackson et al. 2001, Hughes et al. 2003, Feng et al. 2004, Azanza et al. 2005), there is considerable ecological as well as socio-economic pressure to identify alternative and more sustainable livelihoods for human coastal populations. Aquaculture species that do not require exogenous inputs of nutrients, such as shellfish (Bell and Gervis 1999, Feng et al. 2004) and seaweeds (Feng et al. 2004, Pickering et al. 2007) are attractive on environmental grounds. Nonetheless, in many places in the Pacific where they occur, these relatively low-impact activities are still largely in an experimental phase (Bell and Gervis 1999, Pickering et al. 2007), although there are notable exceptions (Doty 1977 , Trono 1999, Feng et al. 2004, Pickering et al. 2007). The reasons behind failed attempts to develop seaweed culture usually have a strong cultural and/or socio-economic basis (McManus et al. 2002, Pickering 2006, Pickering et al. 2007).

\section{The invasion process}

\section{The questions posed}

- Are there common life-history or genetic traits of successful invaders?

- Why do some species become invasive while others do not?

- Is it possible to predict the next pest seaweed?

- Are there common mechanisms underpinning seaweed invasions?

- Why do some communities appear to be more susceptible to incursions than others?

- Do the traits of the recipient community influence invasion rates?

As is the case with terrestrial plants (e.g., Crawley 1987, Mack et al. 2000), there is no consistent set of lifehistory or morphological traits, or particular taxonomic affinities, that define invasive seaweeds (Valentine et al. 2007). Thus, it remains unclear why some species are highly invasive while other, even closely related, species (e.g., Trowbridge 1998) are not. By corollary, the most reliable means of identifying a "next pest" seaweed is through reference to existing patterns of invasion rather than consideration of species' traits in isolation. If there are any broad traits common to most (but not all) invasive seaweeds, it is the capacity for rapid growth and means of effecting both short and long-distance dispersal (Valentine et al. 2007), but many seaweeds manifest these properties without showing any sign of being invasive. Moreover, even the same species can be invasive in one area but not in another (e.g., Trowbridge 1998, Chapman 1999) or, in the same area, at one time but not another [e.g., Undaria pinnatifida (Harvey) Suringar, CR Johnson, pers. obs.]. Collectively, these observations suggest that invasion might have as much to do with the properties of the recipient community as of the invader itself and, of course, this has been a topic of much debate since Elton's (1958) first discussion of the idea (e.g., Levine and D'Antonio 1999, Levine 2000, Stachowicz and Tilman 2005, Fridley et al. 2007).
The results of Dunstan and Johnson's (2007) models substantiate the suggestions of Davis et al. (2000) and Davies et al. (2005) that resource availability is a critical determinant of invasion success and, in particular, that the likelihood of invasion increases with variability in resource availability. For nearly all seaweed species where there is empirical evidence of the mechanism of invasion, disturbance to native species in the recipient community is a key feature (Valentine et al. 2007). Caulerpa taxifolia (M. Vahl) C. Ag. in the Mediterranean may be the only seaweed where invasion does not depend on disturbance breaking a native species' monopoly on resources (see Valentine et al. 2007), but even here resistance to invasion is greater in areas where cover of native seagrass or macroalgae is high (deVilléle and Verlaque 1995, Ceccherelli and Cinelli 1999, Ceccherelli et al. 2002), and there is evidence that high density stands do indeed depend on disturbance to limit the growth of native species (deVilléle and Verlaque 1995, Jaubert et al. 2003). Thus, it appears that invasive seaweeds are not especially competitive; competitive displacement of native seaweeds de novo by alien invasive seaweeds occurs rarely, if at all. At least in some quarters, a similar view is emerging for terrestrial plants (Bruno et al. 2005).

To date, theoretical considerations and empirical observations are consistent with the idea that the risk of seaweed invasion is related to variability in resource availability (Dunstan and Johnson 2007, Valentine et al. 2007), but further carefully designed and executed experiments are required to more rigorously test these ideas. If variability in resource availability through disturbance, or any other mechanism that causes morbidity or mortality of native seaweeds, is ultimately shown to be the key predictor of invasion success, then this may explain apparent anomalies such as why a species is invasive in one area but not another, and why some communities appear more easily invaded than others. It would also explain why risk of invasion might not be predicted by the richness of the recipient community (Dunstan and Johnson 2007). The pattern of fluctuation in resource availability at any given locale will depend at least on the properties of the occupying native species and interactions among them, patterns of disturbance, and variability in physical properties such as temperature, wave action, and nutrient loading.

Complex responses to several experiments suggest that considerations of invasion dynamics need to address separately the different stages of invasion since the mechanisms facilitating ongoing persistence of an invader may be different from those underpinning its initial establishment and spread (Valentine et al. 2007). Disturbance to native canopy-forming algae to provide space is necessary for Sargassum muticum (Yendo) Fensholt and Codium fragile ssp. tomentosoides (van Goor) P.C. Silva to establish at high densities, and presumably to spread beyond initial establishment. Having established a closed canopy, both species can effectively inhibit re-establishment of native seaweeds, at least in the short term (reviewed by Valentine et al. 2007). In Tasmania, Undaria pinnatifida also requires disturbance to native seaweeds to establish at high densities but, once established, it does not require ongoing disturbance to 
maintain its dominance. This is because a matrix of sediment and filamentous algae builds up on the substratum when native canopy-forming species are removed. This matrix inhibits development of native canopy-forming seaweeds, even in the absence of both disturbance (sea urchins) and Undaria pinnatifida and when the inoculum of spores from native seaweeds is enhanced (Valentine and Johnson 2005a,b). However, this effect is scale dependent. If native canopy forming seaweeds are removed in small patches $\left(16 \mathrm{~m}^{2}\right)$ then $U$. pinnatifida establishes and the sediment matrix develops, but within two years the native seaweeds displace the invader to recover dominance (Valentine and Johnson 2003). However, when native algae are removed on a much larger scale, $U$. pinnatifida establishes, the sediment matrix develops, and native canopy forming seaweeds do not recover (Valentine and Johnson 2005a).

The explanation for this non-linear response is unclear. Moreover, it is difficult to estimate the prevalence of nonlinearities of this kind because too few experiments are undertaken to detect them. They certainly add complexity to the nature of invasion dynamics. Similarly, shortterm responses to manipulations at small scales may not be evident over longer periods or at larger scales. If all patches where Codium fragile ssp. tomentosoides (Chapman et al. 2002, Levin et al. 2002) or Sargassum muticum (Britton-Simmons 2004) established were able to inhibit recruitment of native seaweeds indefinitely, then patches of the invader might be expected to persist and maintain their dominance of "captured" sites. This mechanism would result in the gradual but inexorable displacement of native seaweeds over large scales, but this has not been observed for either species. The complete dynamic is more complex than is indicated by short-term experiments. Clearly, detailed and enlightened understanding of invasion processes requires careful experimentation and observations over the long term. There is yet much to be done to fully comprehend the nuances of the invasion dynamics of seaweeds. But even with a more complete knowledge, it is unlikely that particular seaweed invasions will ever be predictable. In this, invasions by seaweeds are no different from those of other kinds of organisms (Gilpin 1990).

\section{Consequences of invasions}

\section{The questions posed}

- What are the ecological, genetic and economic consequences of seaweed invasions?

- Can we expect existing and, in particular, emerging techniques in genetics and genomics to provide a much deeper understanding of seaweed invasions?

If there is issue about the real nature of worldwide biogeographic patterns of alien seaweeds, the uncertainty about the impacts of alien species is even more profound. It could be argued that, since the direct impacts of very few alien species have been considered at all ( $\sim 17$ of the $\sim 260$ alien species identified) while even fewer ( $\sim 4$ species) have been studied in any real depth with appropriate effort given to both experimental work and surveys (Schaffelke and Hewitt 2007), it is premature if not wholly invalid to attempt any general synthesis of the impact of alien seaweeds. However, it seems clear that, like most other groups of alien species including terrestrial plants (e.g., Williamson and Fitter 1996, Gurevitch and Padilla 2004, Bruno et al. 2005), the great majority of alien seaweeds are not highly invasive and are unlikely to become pests. Indeed, the highly skewed attention to a minority of alien seaweed species arises because effort has focussed on those few that appear most likely to be problematic. While there are undoubtedly as yet undetected ecological impacts of alien seaweeds, it is just as certain that a greater number of species would have been investigated more fully to date if there were clear signs of them becoming invasive as opposed to establishing as another "background" alien species.

Of those that have been investigated, effects have varied from significant reductions in both abundance and diversity of native species at a local scale, to no detectable effect, to local enhancement of invertebrate and fish biomass and/or diversity (see Schaffelke and Hewitt 2007, Table 1). In several cases, the introduced seaweed seems to simply increase the standing biomass of total algae. No invasive seaweed has had what could be described as massive effects on biodiversity on a large scale.

While it is clear that some seaweeds have significant ecological impacts, at least locally, current evidence suggests that their impacts might not be as great as several marine animals, particularly some filter-feeding marine molluscs [e.g., the Asian clam Potamocorbula amurensis (Schrenck), Nichols et al. 1990, and New Zealand screwshell Maoricolpus roseus (J.R.C. Quoy et J.P. Gaimard, A. Reid and C.R. Johnson, unpublished data], and generalist predators in pelagic (e.g., the ctenophore Mnemiopsis leidyi, Shiganova 1998, Daskalov 2002, 2003) and benthic (e.g., Northern Pacific seastar, Asterias amurensis A. Agassiz; Ross et al. 2003) habitats. All of these animals have the capacity to effect deleterious impact on richness, diversity and ecosystem functioning over large spatial scales. Of course, comparing the impact of seaweeds in one area with that of animals in another is problematic because it is not possible to distinguish impacts as a property of the invader from impacts related to the nature of the recipient community. However, the pattern of greater impacts by animals than plants is sometimes evident in the same system. In Tasmania for example, despite the relatively rapid spread of Undaria pinnatifida and its capacity to form a closed canopy in dense stands (Sanderson 1990, Valentine and Johnson 2003, Hewitt et al. 2005), its overall effect has arguably been small compared to that of introduced benthic marine animals such as $A$. amurensis (Ross et al. 2003), M. roseus and the European green crab Carcinus maenus (Linn.) (Thresher et al. 2003). C. maenus has a voracious appetite for small bivalves including mussels, oysters and cockles, and appears to displace a similarly sized native crab species, Paragapsus gaimardii (Milne Edwards) (Walton et al. 2002). If these patterns are found to hold more generally, then it will parallel the pattern from terrestrial systems where invasive animals, particularly generalist predators, 
have greater direct impacts than plants. In other words, invasive top-down effects may be more important than invasive bottom-up effects in changing the configurations of recipient benthic communities.

There remains much to do to properly understand the impacts of invasive seaweed species. Their socio-economic impacts have hardly been addressed at all (Schaffelke et al. 2007). Not only have the impacts of few species been examined thoroughly, but most studies have focussed on the direct impacts on the abundance and diversity of natives. In considering effects on diversity, most work has examined local alpha diversity, while beta and gamma diversity have been ignored. In many cases, local alpha diversity might decrease while gamma diversity increases. For example, in Nova Scotia Codium fragile spp. tomentosoides has been spectacular in its displacement of the previously dominant kelps (largely Saccharina longicruris (Pyl.) Kuntze; see Johnson and Mann 1988 [as: Laminaria longicruris Pyl.]) in patches. This green alga does so by capitalizing on disturbances from grazers, or in response to dieback of kelp as a result of smothering of their photosynthetic tissue by the introduced bryozoan Membranipora membranacea Linn. (see Chapman et al. 2002). Native seaweeds, particularly kelps, are less abundant in areas taken over by Codium, and so at a local scale alpha diversity is reduced. A similar phenomenon has been observed in the Gulf of Maine further to the south (e.g., Levin et al. 2000). While Codium can form meadows of 100s-1000s of square meters in extent, in Nova Scotia replacement of kelps at this scale has occurred mostly in two bays (Mahone and St Margarets Bay), but only in wave sheltered areas in shallow water ( $\leq 8 \mathrm{~m}$; R. Scheibling, pers. comm.). Thus, gamma diversity may well have increased.

Descriptions of impacts on diversity and abundances are a useful starting point, but at least as important are the effects on ecosystem functioning and dynamics. However, these aspects are rarely examined, no doubt because of the effort and, in some cases, technology required. How are primary and secondary production, and resistance and resilience stability (sensu Dayton et al. 1984) affected by invasives? What is the nature of indirect effects, and of synergistic effects of co-occurrence of several alien seaweeds? The only measurable effect of the establishment of some alien species is apparently to increase total algal cover and local richness (see Schaffelke and Hewitt 2007). But do relatively benign alien species like this simply accumulate indefinitely in a linear manner, or is some threshold attained where effects become non-linear? Can otherwise noninvasive seaweeds become highly invasive in the face of significant interactions with anthropogenic modifications to the marine environment, e.g., disturbance and eutrophication? Is there any evidence of "invasional meltdown" (Simberloff and Von Holle 1999; see also Simberloff 2006) whereby establishment of some alien species increases the likelihood of subsequent incursions? Are there significant evolutionary consequences for the invader in establishing in new areas, and for native species as seaweed floras become increasingly homogenized with ongoing accumulation of aliens?

These are all important questions that are poorly addressed, not only for seaweeds but for invaded sys- tems in general. But they are also difficult questions to tackle, and typically require complex experimental fieldbased studies, often over several years combined with empirical surveys at several scales. We are hopeful that researchers will have the courage to address these questions in the near future. With the rapid emergence and uptake of new techniques in molecular genetics, there is every chance that some of the evolutionary questions, particularly those relating to interactions between genotype, phenotype and environment, might be resolved before the ecological ones (Hofmann et al. 2005, Booth et al. 2007). This would be a welcome development given that the genetic consequences of seaweed invasions, including effects on gene pool composition, genome organization and mating systems, are currently so poorly appreciated (Booth et al. 2007).

\section{Human responses to the threat and occurrence of invasions}

\section{The questions posed}

- How have seaweed invasions been tracked, and can existing approaches be improved?

- Is it possible to predict the course of an invasion?

- What are sensible approaches to reducing risk of further introductions?

Responses to the threat of alien invasive seaweeds have included (1) attempts to mitigate the risk of alien species becoming established in the first place, (2) the development and application of science and technology to better predict "next pests", more rapidly detect alien species before they have opportunity to spread, and better understand the space-time dynamics of invasions, and (3) attempts to eliminate or control invasive seaweeds when they do establish in a new locale.

The earlier intervention occurs in the chain of events described by uptake at a donor site $\rightarrow$ translocation by a vector $\rightarrow$ release at a donor site $\rightarrow$ establishment at donor site, the easier and less expensive it usually is to thwart potential introductions. Ships have long been recognized as vectors for translocation of marine species (e.g., Ostenfeld 1908) but, as we emphasized earlier, practical responses to minimize translocation of species by ships have focused largely on ballast water (e.g., Cangelosi et al. 2007, Gollasch et al. 2007), despite the fact that hull fouling is a major source of introduction of seaweeds and many other kinds of marine organisms (Hewitt et al. 2007). Particularly as TBT-based antifouling is phased out, and given the cost of engineering solutions to hull fouling, translocation of alien seaweeds by shipping is likely to be with us for a long time to come unless hull scrubbing or other hull treatment is forced through regulation, which seems unlikely, at least in the medium term (see Doelle et al. 2007). This is despite the economic incentive to reduce drag, and thus fuel costs, by minimising hull fouling. Notwithstanding the problem of hull fouling, international and most national policy and law makers are acutely aware of the risks associated with translocation of marine species. They also recognise the fragmented nature and lack of integration of existing reg- 
ulations aimed at controlling translocation of marine species across national borders (Doelle et al. 2007). Researchers must take all opportunities to urge their governments to establish regulatory frameworks that minimize the risk of translocating species among bioregions, and to cooperate with other nations in effecting this goal. The lead taken in establishing pertinent legislation by the governments of Australia, New Zealand, Canada and Germany needs to be replicated globally.

Rapid response to new introductions requires being able to identify an alien species as soon as it establishes. This requires not only implementation of some kind of screening procedure, which might sensibly be based on risk management principles, but also the existence of appropriate taxonomic and, increasingly, molecular genetics skills. With declining funding for taxonomy and fewer taxonomists being trained worldwide (Godfray 2002, Hopkins and Freckleton 2002), a potential problem in early detection is looming rapidly. There have been successful, if expensive, campaigns to completely eradicate alien invasive seaweeds, but in every case this has relied on early detection (Anderson 2007).

There are limited options to control invasive seaweeds once the opportunity for eradication has passed (Anderson 2007). In this context it is interesting that modelling seaweed invasions and various options for their control has not featured in responding to establishment of alien seaweeds. This omission is puzzling given that modelling could be highly beneficial in providing understanding of the epidemiology of invasions, predicting the course of seaweed invasions and thus improving strategic responses to invasions and informing optimum allocation of effort for surveillance, and in helping assess various options for control. Models would be of particular value if they could be calibrated against the known dynamics of initial range expansion. In this context we note that a plethora of techniques has been brought to tracking seaweed invasions (Meinesz 2007), but little attempt has been made to use this information in models. Given problems with remotely sensing invasive seaweeds, there is necessarily a large "on ground" effort if an accurate estimate of the pattern of range expansion of an invasive seaweed is to be ascertained (Meinesz 2007). The high cost of obtaining these kinds of data from field-based monitoring begs optimum use of the information, and this surely must include modelling. There exist a plethora of both well-established and emerging techniques to predict species' distributions (Guisan and Zimmerman 2000, Elith et al. 2006), model the epidemiology of spread, including the effects of unpredictable long-distance dispersal events (e.g., Russell et al. 2005) which might be a hallmark of many marine invasions (Kinlan and Gaines 2003), and account for the spatial structure of populations in considering control options (e.g., Travis and Park 2004).

\section{Coda}

We have identified a raft of questions and challenges that will, hopefully, help shape research efforts into invasive seaweeds into the future. No task is more pressing how- ever than the need for better integration of research on invasive seaweed species with "mainstream" theory on ecological invasions. Seaweed ecologists are occupied with many of the questions that are more broadly considered in invasion biology; how the likelihood, nature and impact of invasions are influenced by propagule pressure, the nature of the recipient community, the role of disturbance, and biology of the invader. The critical gains in understanding, not only of seaweed invasions but of invasion dynamics in the broad, will arise through a heady mix and purposeful integration of in situ fieldbased experiments, empirical observation at a range of scales, and ecological theory.

\section{References}

Anderson, L.W.J. 2007. Control of invasive seaweeds. Bot. Mar. 50: 418-437.

Azanza, R.V., Y. Fukuyo, L.G. Yap and H. Takayama. 2005. Prorocentrum minimum bloom and its possible link to a massive fish kill in Bolinao, Pangasinan, Northern Philippines. Harmful Algae 4: 519-524.

Bell, J.D. and M. Gervis. 1999. New species for coastal aquaculture in the tropical Pacific - constraints, prospects and considerations. Aquacult. Int. 7: 207-223.

Britton-Simmons, K.H. 2004. Direct and indirect effects of the introduced alga Sargassum muticum on benthic, subtidal communities of Washington State, USA. Mar. Ecol. Prog. Ser. 277: 61-78.

Bruno, J.F., J.D. Fridley, K.D. Bromberg and M.D. Bertness. 2005. Insights into biotic interactions from studies of species invasions. In: (D.F. Sax, J.J. Stachowicz and S.D. Gaines, eds) Species invasions. Insights into ecology, evolution and biogeography. Sinauer Associates, Sunderland. pp. 13-40.

Booth, D., J. Provan and C.A. Maggs. 2007. Molecular approaches to the study of invasive seaweeds. Bot. Mar. 50: 385-396.

Cangelosi, A.A., N.L. Mays, M.D. Balcer, E.D. Reavie, D.M. Reid, R. Sturtevant and X. Gao. 2007. The response of zooplankton and phytoplankton from the North American Great Lakes to filtration. Harmful Algae 6: 547-566.

Ceccherelli, G. and F. Cinelli. 1999. Effects of Posidonia oceanica canopy on Caulerpa taxifolia size in a north-western Mediterranean bay. J. Exp. Mar. Biol. Ecol. 240: 19-36.

Ceccherelli G., L. Piazzi and D. Balata. 2002. Spread of introduced Caulerpa species in macroalgal habitats. J. Exp. Mar. Biol. Ecol. 280: 1-11.

Chapman, A.S. 1999. From introduced species to invader: what determines variation in the success of Codium fragile ssp. tomentosoides (Chlorophyta) in the North Atlantic Ocean? Helgol. Meeresunters. 52: 277-289.

Chapman, A.S., R.E. Scheibling and A.R.O. Chapman. 2002. Species introductions and changes in the marine vegetation of Atlantic Canada. In: (R. Claudi, P. Nantel and E. MuckleJeffs, eds) Alien invaders in Canada's waters, wetlands and forests. Canadian Forest Service, Ottawa. pp. 133-148.

Crawley, M.J. 1987. What makes a community invasible? In: (A.J. Gray, M.J. Crawley and P.J. Edwards, eds) Colonization, succession and stability. Blackwell Scientific, Oxford. pp. 429-453.

Daskalov, G.M. 2002. Overfishing drives a trophic cascade in the Black Sea. Mar. Ecol. Prog. Ser. 225: 53-63.

Daskalov, G.M. 2003. Long-term changes in fish abundance and environmental indices in the Black Sea. Mar. Ecol. Prog. Ser. 255: 259-270.

Dayton, P.K., V. Currie, T. Gerrodette, B.D. Keller, R. Rosenthal, D. Ven Tresca. 1984. Patch dynamics and stability of some California kelp communities. Ecol. Monog. 54: 253-289. 
Davies, K.F., P. Chesson, S. Harrison, B.D. Inouye, B.A. Melbourne and K.J. Rice. 2005. Spatial heterogeneity explains the scale dependence of the native-exotic diversity relationship. Ecology 86: 1602-1610.

Davis, M.A., J.P. Grime and K. Thompson. 2000. Fluctuating resources in plant communities: a general theory of invasibility. J. Ecol. 88: 528-534.

deVilléle, X. and M. Verlaque. 1995. Changes and degradation in a Posidonia oceanica bed invaded by the tropical alga Caulerpa taxifolia in the North Western Mediterranean. Bot. Mar. 38: 79-87.

Doelle, M., M.L. McConnell and D.L. VanderZwaag. 2007. Invasive seaweeds: global and regional law and policy responses. Bot. Mar. 50: 438-450.

Doty, M.S. 1977. Seaweed resources and their culture in the South China Sea region. South China Sea fisheries development and coordinating programme, Project Report SCS/ 77/WP/60. FAO, 36 pp. http://www.fao.org/docrep/field/003/ AC007E/AC007E00.htm.

Dunstan, P.K. and C.R. Johnson. 2007. Mechanisms of invasion: can the recipient community influence invasion rates? Bot. Mar. 50. 361-372.

Elith, J., C.H. Graham, R.P. Anderson, M. Dudík, S. Ferrier, A. Guisan, et al. 2006. Novel methods improve prediction of species' distributions from occurrence data. Ecography 29: $129-151$.

Elton, C.S. 1958. The ecology of invasions by animals and plants. Methuen, London.

Feng, Y.Y., L.C. Hou, N.X. Ping, T.D. Ling and C.I. Kyo. 2004. Development of mariculture and its impacts in Chinese coastal waters. Rev. Fish Biol. Fisheries 14: 1-10.

Fridley, J.D., J.J. Stachowicz, S. Naeem, D.F. Sax, E.W. Seabloom, M.D. Smith, T.J. Stohlgren, D. Tilman and B. Von Holle. 2007. The invasion paradox: reconciling pattern and process in species invasions. Ecology 88: 3-17.

Gilpin, M. 1990. Ecological prediction. Science 248: 88-89.

Godfray, H.C.J. 2002. Challenges for taxonomy. Nature 417: 17-19.

Gollasch, S., M. David, M. Voigt, E. Dragsund, C. Hewitt and Y. Fukuyo. 2007. Critical review of the IMO international convention on the management of ships' ballast water and sediments. Harmful Algae 6: 585-600.

Guisan, A. and N.E. Zimmerman. 2000. Predictive habitat distribution models in ecology. Ecol. Modelling 135: 147-186.

Gurevitch, J. and D.K. Padilla. 2004. Are invasive species a major cause of extinctions? Trends Ecol. Evol. 19: 470-474.

Hewitt, C.L., M.L. Campbell, F. McEnnulty, K.M. Moore, N.B. Murfet, B. Roberston and B. Schaffelke. 2005. Efficacy of physical removal of a marine pest: the introduced kelp Undaria pinnatifida in a Tasmanian Marine Reserve. Biol. Invasions 7: 251-263

Hewitt, C.L., M.L. Campbell and B. Schaffelke. 2007. Introductions of seaweeds: accidental transfer pathways and mechanisms. Bot. Mar. 50: 326-337.

Hofmann, G.E., J.L. Burnaford and K.T. Fielman. 2005. Genomics-fueled approaches to current challenges in marine ecology. Trends Ecol. Evol. 20: 305-311.

Hopkins, G.W. and R.P. Freckleton. 2002. Declines in the number of amateur and professional taxonomists: implications for conservation. Anim. Conserv. 5: 245-249.

Hughes, T.P., A.H. Baird, D.R. Bellwood, M. Card, S.R. Connolly, C. Folke, R. Grosberg, et al. 2003. Climate change, human impacts, and the resilience of coral reefs. Science 301: 929-933.

Jackson, J.B.C., M.X. Kirby, W.H. Berger, K.A. Bjorndal, L.W. Botstord, B.J. Bourque, et al. (2001). Historical overfishing and the recent collapse of coastal ecosystems. Science 293: $629-637$.

Jaubert, J.M., J.R.M. Chisholm, A. Minghelli-Roman, M. Marchioretti, J.H. Morrow and H.T. Ripley. 2003. Re-evaluation of the extent of Caulerpa taxifolia development in the northern Mediterranean using airborne spectrographic sensing. Mar. Ecol. Prog. Ser. 263: 75-82.

Johnson, C.R. and A.R.O. Chapman. 2007. Seaweed invasions: introduction and scope. Bot. Mar. 50: 321-325.

Johnson, C.R. and K.H. Mann. 1988. Diversity, patterns of adaptation, and stability of Nova Scotian kelp beds. Ecol. Monogr. 58: $129-154$

Kinlan, B.P. and S.D. Gaines. 2003. Propagule dispersal in marine and terrestrial environments: a community perspective. Ecology 84: 2007-2020.

Levin, P.S., J.A. Coyer, R. Petrik and T.P. Good. 2002. Community-wide effects of nonindigenous species on temperate rocky reefs. Ecology 83: 182-3193.

Levine, J.M. 2000. Species diversity and biological invasions: relating local process to community pattern. Science 288 : 852-854.

Levine, J.M. and C.M. D'Antonio. 1999. Elton revisited: a review of evidence linking diversity and invasibility. Oikos 87: 15-26.

Mack, R.N., D. Simberloff, W.M. Lonsdale, H. Evans, M. Clout and F. Bazzaz. 2000. Biotic invasions: causes, epidemiology, global consequences and control. Ecol. Appl. 10: 689-710.

McManus, L.T., E.M. Ferrer, L.P. dela Cruz and A. Cadavos. 2002. The Bolinao community-based coastal resources management project (initial phase): Towards an interdisciplinary approach. In: (E. Ferrer, L. dela Cruz, M. Domingo, eds) Seeds of hope: a collection of case studies on communitybased coastal resources management in the Philippines. CBCRM Resource Center, University of the Philippines, pp. 150-179. www.cbcrmlearning.org/documents/pdf/bolinao. pdf.

McManus, J.W. 1997. Tropical marine fisheries and the future of coral reefs: a brief review with emphasis on Southeast Asia. Coral Reefs 16 (Suppl.): S121-S127.

Meinesz, A. 2007. Methods for identifying and tracking seaweed invasions. Bot. Mar. 50: 373-384.

Nichols, F.H., J.K. Thompson and L.E. Schemel. 1990. Remarkable invasion of San Francisco Bay (California, USA) by the Asian clam Potamocorbula amurensis. II. Displacement of a former community. Mar. Ecol. Prog. Ser. 66: 95-101.

Ostenfeld, C.H. 1908. On the immigration of Biddulphia sinensis Grev. and its occurrence in the North Sea during 1903-1907. Meddelelser fra Kommissionen for Havundersogelser. Plankton 1: 1-25.

Pickering, T.D. 2006. Advances in seaweed aquaculture among Pacific Island countries. J. Appl. Phycol. 18: 227-234.

Pickering, T.D., P. Skeleton and R.J. Sulu. 2007. Intentional introductions of commercially harvested alien seaweeds. Bot. Mar. 50: 338-350.

Ribera, M.A. and C.-F. Boudouresque. 1995. Introduced marine plants, with special reference to macroalgae: mechanisms and impact. Prog. Phycol. Res. 11: 187-268.

Ross, D.J., C.R. Johnson and C.L. Hewitt. 2003. Assessing the ecological impacts of an introduced seastar: The importance of multiple methods. Biol. Invasions 5: 3-21.

Russell, C.A., D.L. Smith, J.E. Childs and L.A. Real. 2005. Predictive spatial dynamics and strategic planning for raccoon rabies emergence in Ohio. PLoS Biology 3: 382-388.

Sanderson, J.C. 1990. A preliminary survey of the distribution of the introduced macroalga, Undaria pinnatifida Harvey Suringer on the East Coast of Tasmania, Australia. Bot. Mar. 33: 153-157.

Schaffelke, B. and C.L. Hewitt. 2007. Impacts of introduced seaweeds. Bot. Mar. 50: 397-417.

Schaffelke, B., J.E. Smith and C.L. Hewitt. 2006. Introduced macroalgae - a growing concern. J. Appl. Phycol. 18: 529541.

Shiganova, T.A. 1998. Invasion of the Black Sea by the ctenophore Mnemiopsis leidyi and recent changes in pelagic community structure. Fish. Oceanogr. 7: 305-310. 
Simberloff, D. 2006. Invasional meltdown 6 years later; important phenomenon, unfortunate metaphor, or both? Ecol. Lett. 9: 912-919.

Simberloff, D. and B. Von Holle. 1999. Positive interactions of nonindigenous species: invasional meltdown? Biol. Invasions 1: 21-32.

Stachowicz, J.J. and D. Tilman. 2005. Species invasions and the relationships between species diversity, community saturation, and ecosystem functioning. In: (D.F. Sax, J.J. Stachowicz and S.D. Gaines, eds) Species invasions insights into ecology, evolution and biogeography. Sinauer Associates, Sunderland. pp. 41-64.

Thresher, R., C. Proctor, G. Ruiz, R. Gurney, C. MacKinnon, W. Walton, L. Rodriguez and N. Bax. 2003. Invasion dynamics of the European shore crab, Carcinus maenas, in Australia. Mar. Biol. 142: 867-876.

Travis, J.M.J. and K.J. Park. 2004. Spatial structure and the control of invasive alien species. Anim. Conserv. 7: 321-330.

Trono, G.C. 1999. Diversity of the seaweed flora of the Philippines and its utilization. Hydrobiologia 398/99: 1-6.

Trowbridge, C.D. 1998. Ecology of the green macroalga Codium fragile (Suringar) Hariot 1989: invasive and non-invasive subspecies. Oceanogr. Mar. Biol. Ann. Rev 36: 1-64.
Valentine, J.P. and C.R. Johnson. 2003. Establishment of the introduced kelp Undaria pinnatifida in Tasmania depends on disturbance to native algal assemblages. J. Exp. Mar. Biol. Ecol. 295: 63-90.

Valentine, J.P. and C.R. Johnson. 2005a. Persistence of the exotic kelp Undaria pinnatifida does not depend on sea urchin grazing. Mar. Ecol. Prog. Ser. 285: 43-55.

Valentine, J.P. and C.R. Johnson. 2005b. Persistence of sea urchin (Heliocidaris erythrogramma) barrens on the east coast of Tasmania: inhibition of macroalgal recovery in the absence of high densities of sea urchins. Bot. Mar. 48: 106115.

Valentine, J.P., R.H. Magierowski and C.R. Johnson. 2007. Mechanisms of invasion: establishment, spread and persistence of introduced seaweed populations. Bot. Mar. 50: 351360

Walton, W.C., C. MacKinnon, L.F. Rodriguez, C. Proctor and G.M. Ruiz. 2002. Effect of an invasive crab upon a marine fishery: green crab, Carcinus maenas, predation upon a venerid clam, Katelysia scalarina, in Tasmania (Australia). J. Exp. Mar. Biol. Ecol. 272: 171-189.

Williamson, M. and A. Fitter. 1996. The varying success of invaders. Ecology 77: 1661-1666. 